\title{
ACCIÓN COLECTIVA, ESPACIO PÚBLICO Y ECONOMÍA SOLIDARIA EN EL SUR DE BRASIL
}

\author{
Ana Mercedes Sarria Icaza \\ anasarriaicaza@yahoo.com.br \\ CENTRO UNIVERSITARIO LA SALLE \\ UNILASALLE, BRASIL
}

\section{RESUMEN}

Este texto analiza el proceso de emergencia y organización de la economía solidaria en Brasil, tomando como referencia la experiencia del estado de Rio Grande do Sul, en donde una serie de factores —relacionados con la historia, la dinámica social y política y los actores locales- se conjugan con procesos más amplios en los ámbitos nacional e internacional y hacen posible la ampliación significativa de lo que aquí se denomina economía popular solidaria.

El trabajo identifica un conjunto de contradicciones y desafíos presentados para la economía solidaria hoy, como un espacio de acción colectiva integrada en procesos de construcción y ampliación de la democracia, en los cuales no es más posible disociar lo social, lo político y lo económico.

Palabras clave: Economía popular solidaria, acción colectiva, democracia. 


\begin{abstract}
This text analyzes the process of emergence and organization of the solidary economy in Brazil, taking as reference the experience of the state of Rio Grande do Sul, in which a series of factors - related to history, the social and political dynamic, and local actors- converge with broader processes in the national and international spheres and make possible the significant expansion of what here is called the popular solidary economy.

The article identifies a set of contradictions and challenges presented today for the solidary economy, as a space of collective action integrated in processes of construction and expansion of democracy, in which it is no longer possible to disassociate the social, the political and the economic.
\end{abstract}

Key words: Popular solidary economy, collective action, democracy. 


\section{INTRODUCCIÓN}

Como toda práctica social, la economía solidaria solo puede ser entendida analizando sus orígenes, identificando el contexto social, político y económico, los diferentes actores implicados, sus confluencias y contradicciones, los procesos que hicieron posible que asumiera una misma forma de nombrarse, la trayectoria de esa construcción, nunca linear, siempre contradictoria y dinámica.

Un análisis de este proceso en Brasil permite explicar el impulso de la economía solidaria a finales de la década de 1990 a partir de la conjugación de una serie de elementos, entre los cuales se destacan: en primer lugar, un conjunto de «actores predispuestos a la acción», que fueron protagonistas de las luchas por la democratización del país en los años anteriores; en segundo lugar, la «apertura del cuadro político-institucional», y en tercero, una «coyuntura económica» marcada por el aumento del desempleo y la reducción de derechos sociales producto de la crisis del modelo de regulación fordista.

A estos elementos se suma la «emergencia y revitalización de un movimiento de la sociedad civil en el ámbito mundial», articulado en torno al cuestionamiento del proceso de globalización en curso, con todas sus contradicciones y consecuencias sociales, económicas, ambientales, que tiene como punto de encuentro la ciudad de Porto Alegre, en ediciones sucesivas del Foro Social Mundial.

El presente trabajo analiza los procesos concretos de emergencia y construcción de la economía solidaria en Brasil y específicamente en Rio Grande do Sul, un territorio que se ha mostrado particularmente dinámico, tanto en términos de organización de actores colectivos como de implementación de políticas públicas y de crecimiento progresivo de prácticas socioeconómicas asociativas. 
Nuestro punto de partida es el componente de acción colectiva que caracteriza la economía solidaria, el cual entendemos como fundamental para comprender su dinámica y su potencial trasformador. En este sentido, profundizamos sus desafíos democráticos y su relación con la construcción de espacios públicos autónomos, lugar de expresión y de debate entre ciudadanos en la búsqueda de otras formas de producir y distribuir la riqueza.

El análisis de la génesis de la economía solidaria en Rio Grande do Sul permite identificar tres momentos principales, a partir de los cuales se estructura este artículo: los impulsos iniciales de la década de los 80, el surgimiento y organización en la década de los 90, y la estructuración e institucionalización en la primera década del nuevo milenio. En este proceso, buscamos entender la configuración actual de la red de actores implicados, sus relaciones con las políticas públicas y su capacidad de recrear espacios de relaciones sociales y económicas capaces de producir trasformaciones más amplias, en diferentes esferas y niveles.

\section{LA ECONOMÍA SOLIDARIA COMO PROCESO DE ACCIÓN COLECTIVA EN LA LUCHA POR LA DEMOCRATIZACIÓN DE LA ECONOMÍA}

En general, las construcciones teóricas sobre la economía solidaria en los últimos años enfatizan la necesidad de repensar la relación entre lo económico y lo social, superando los límites del pensamiento neoliberal dominante que restringe la economía a la lógica del mercado. La crisis del modelo de regulación fordista pone justamente en evidencia la inviabilidad de la «utopía del mercado autoregulado», confirmando aquello que Polanyi había observado: que las instituciones que encarnan esa utopía «no podrían existir por mucho tiempo sin aniquilar el material humano y natural de la sociedad 
[porque] habrían destruido físicamente el hombre y desvastado el ambiente» (apud Santos 2002, p. 24).

El uso de los conceptos, sin embargo, es diverso, prefiriéndose uno u otro según las diferentes realidades y tradiciones institucionales y culturales. Como señala Coraggio (2001):

En situaciones de debilidad teórica, el nominalismo impera. Las nuevas o las viejas ideas renacidas vienen envueltas en nuevos nombres o en nombres redescubiertos. Las diferencias de utopías, intereses o propuestas, tienden a diferenciarse por ciertas palabras clave: ¿Economía social? ¿Solidaria? ¿Popular?, ¿del Trabajo? ¿Empresa social? En esto la dilucidación conceptual hace necesario reconocer que también los mismos términos tienen significados distintos —a lo largo del tiempo en la misma sociedad, y entre sociedades contemporáneas-, por varias razones: a) objetivas, porque se refieren a realidades culturalmente distintas, a pesar de que forman parte de un mismo proceso de globalización y trasformación estructural; b) subjetivas, porque se interpretan desde marcos teóricos y/o utopías distintas.

En el caso brasileño, prevalece el uso del término economía solidaria, aunque es posible identificar dos tipos de construcciones teóricas principales: de un lado, aquella que es predominante, en la cual la economía solidaria es entendida como espacio de experimentación de un nuevo «modo de producción» que, basado en el cooperativismo autogestionario, representaría una forma más avanzada de organización para los trabajadores y posibilitaría la superación del modo de producción capitalista. ${ }^{1}$ De otro lado, las propuestas relativas a la «economía popular», que supone el reconocimiento de una pluralidad de formas de organización económica y el rechazo a una visión linear de progreso, reconociendo otros principios económicos además del mercado, como el de la reciprocidad o el de la redistribución. ${ }^{2}$ 
Considerando la diversidad de proyectos para la economía solidaria, entendemos que un desafío importante es justamente reconocer esa pluralidad, profundizando el debate de las alternativas de organización económica sin separarlas de las dinámicas culturales, políticas y sociales en que se insieren. En esta dirección, diferentes autores, ${ }^{3}$ coinciden en destacar el indispensable debate democrático implicado en la discusión de proyectos económicos capaces de cuestionar los fundamentos de la acumulación capitalista actual, colocando en el centro eso que Coraggio (2000) llama de «reproducción ampliada de la vida» y que Peemans (2002) denomina de «otro orden para los pueblos y las personas».

La cuestión democrática es un elemento importante que está presente en la dinámica de la economía solidaria desde sus orígenes y que, en el caso brasileño, se expresa en la alusión a la aspiración de ciudadanía, un término altamente simbólico entre todos los actores implicados. La cuestión de la ciudadanía remite tanto a la necesidad de apertura de los espacios propiamente políticos, históricamente autoritarios y restrictos a elites oligárquicas, cuanto al reconocimiento y el acceso a derechos sociales básicos, históricamente negados a la gran mayoría de la población, en una sociedad en la que el crecimiento económico generó bienestar para pocos.

Las experiencias de economía solidaria permiten traer al espacio público una diversidad de actores sociales, cuyos procesos de organización integran dimensiones económicas, sociales y políticas, y proponen otras formas de producir y distribuir la riqueza, de integrar la economía con la vida. Entendemos que, más que proyectos claros y articulados de una economía alternativa al capitalismo, lo que se construye es un movimiento diverso cuya fuerza fundamental es su capacidad de cuestionar, proponer, experimentar. 


\section{ANTECEDENTES DE LA ECONOMÍA SOLIDARIA EN RIO GRANDE DO SUL.}

\section{LUCHAS SOCIALES, CRISIS ECONÓMICA Y PRÁCTICAS ASOCIATIVAS}

El estado de Rio Grande do Sul se caracteriza por poseer una sociedad civil activa, un movimiento popular fuerte y organizado, un territorio en el que la izquierda ganó espacios crecientes en los últimos veinte años. ${ }^{4}$ En términos socioeconómicos, es uno de los estados brasileños con mejores índices de desarrollo humano y posee una matriz productiva diversificada, fundamentalmente basada en la industria — metalúrgica y de calzado—, el agronegocio — soya, trigo, arroz—, la pecuaria y la pequeña agricultura familiar.

La tradición cooperativa es históricamente significativa, vinculada, desde finales del siglo XIX, a comunidades de inmigrantes alemanes e italianos, e institucionalizándose entre los años 1950 y 1970 con el desarrollo de las grandes cooperativas agrícolas promovidas por la política gubernamental de estímulo a la agroexportación.

La crisis del modelo de desarrollo nacional, iniciada en los años 1980 y profundizada en la década de 1990, se hizo sentir con fuerza en todas las regiones y en todas las esferas de la actividad económica del estado. La profundización de esta crisis económica, el aumento del desempleo y de las desigualdades sociales, fue generando, cada vez con más intensidad, la necesidad de construir opciones de organización económica para los sectores más perjudicados, principalmente en las regiones urbanas y en la pequeña propiedad rural, en momentos en que las promesas neoliberales profundizaban las desigualdades y la pobreza.

Hay así, a partir de los años 80, una revitalización de experiencias asociativas y cooperativas, muchas de las cuales están ligadas a la actuación de movimientos sociales 
y organizaciones no gubernamentales, y constituyen la base de lo que en los años 90 pasó a autoidentificarse como «economía popular solidaria» o, simplemente, «economía solidaria» ${ }^{5}$. Entre las primeras experiencias de economía solidaria pueden ser identificados, a inicios de los años 1980, proyectos vinculados principalmente con Cáritas y la Iglesia Evangélica de Confesión Luterana.

Entre estos, caben destacar los Proyectos Alternativos Comunitarios, PAC, de iniciativa de Cáritas, expresión de un proceso de organización popular que crecía en el campo y la ciudad. La construcción de «proyectos alternativos» está directamente relacionada con un contexto más amplio: de recesión económica, de aumento de las desigualdades y de luchas por la democratización del país.

\footnotetext{
Un contexto de reorganización de la sociedad al inicio de los años 80 , en la lucha contra el régimen militar, cuando se fortalecieron los movimientos populares como alternativas organizativas, valorizando los espacios de la vida cotidiana y de la política. La década de 1980 también fue marcada por la recesión económica acompañada de inflación descontrolada, lo que repercutió directamente en el mercado de trabajo, disminuyendo el crecimiento de los empleos formales y aumentando el número de trabajadores sin contrato de trabajo y de trabajadores por cuenta propia. Fue en ese contexto de quiebra del «milagro económico» y de aumento de la crisis social que surgieron alternativas socioeconómicas de producción, consumo, salud, etcétera (Bertucci y Silva 2003:14).
}

Por otro lado, los PAC surgen también como expresión de un proceso de trasformación de las prácticas asistenciales de la Iglesia católica, interpeladas por la realidad política y socioeconómica de la sociedad brasileña inserta en la década de 1980. 


\begin{abstract}
El sentido revolucionario prestado a la palabra «alternativo» es un testimonio del notable giro de la Iglesia provocado por la opción preferencial por los pobres, es decir, por los no poseedores de medios de producción. Al inicio, la nueva postura no tenía un programa claro de cómo los trabajadores pueden salir de la miseria por sus propias fuerzas. Por eso, ella convoca a las propias comunidades a encontrar las salidas, por la aplicación del antiguo pero todavía hoy indispensable método de ensayo y error, a través de una vasta multiplicación de diferentes «experiencias» (Singer 2002b: 117).
\end{abstract}

Los PAC nacen de diferente forma en las diversas regiones brasileñas, teniendo, en general, como objetivo «apoyar pequeñas iniciativas asociativas, capaces de promover cambios en la vida de las personas a través de la solidaridad»(Bertucci y Silva 2003: 3).

En 1985 se realizó el I Encuentro Estadual de Proyectos Alternativos Comunitarios, y en 1986, con el apoyo de la Iglesia católica alemana, comenzó a funcionar un Fondo de Miniproyectos, destinando recursos para apoyar el funcionamiento de los grupos, en un formato parecido al de microcrédito. Muchos grupos de economía solidaria comenzaron a funcionar apoyados por este Fondo, a partir de proyectos orientados a la organización productiva, asumiendo formas destinadas a la producción o «generación de ingresos» y organizados de forma democrática y asociativa.

Las llamadas «experiencias de generación de ingresos» o «proyectos alternativos comunitarios» de los años 80 emergen claramente marcados por las prácticas de los movimientos sociales de ese periodo, tanto en relación con su base social como en relación con sus promotores, que resultan en una compleja interacción selectiva entre la Iglesia católica, agrupamientos de izquierda y organizaciones no gubernamentales, en 
general abrigando intelectuales y profesionales empeñados en la «causa popular». (Doimo 1995)

La base social de estas experiencias está constituida por los pobres del campo y la ciudad, es decir, «los pequeños agricultores»y los «sectores informales urbanos», los cuales constituyen el núcleo de lo que posteriormente irá a ser llamado de economía solidaria.

La organización de los pequeños agricultores se da a partir de dos ejes: de un lado, la lucha por la tierra para aquellos que no la poseen; y de otro, la agregación de valor para aquéllos con pequeñas propiedades, retomando la tradición asociativa, de cooperación y de ayuda mutua, pero diferenciándose de las prácticas del cooperativismo tradicional. La discusión de las formas cooperativas o asociativas de producción adquiere especial relevancia al final de la década, con los primeros grupos asentados de la reforma agraria organizados en el Movimiento de Trabajadores Sin Tierra, MST. Conforme con Paul Singer:

\footnotetext{
A partir de 1986, comienza la discusión de cómo organizar los asentados con el I Encuentro Nacional de los Asentados, en el cual estuvieron representados 76 asentamientos de 11 estados. A pesar de la resistencia inicial al cooperativismo «por las experiencias negativas del modelo tradicional del cooperativismo, caracterizado como grandes empresas agroindustriales que desarrollaron una política de explotación económica de los agricultores» (Concrab 1999: 6), la discusión evolucionó a favor del cooperativismo, en términos que hoy diríamos ser los de la economía solidaria (2002b: 103).
}

Por otro lado, crece significativamente el número de experiencias entre los sectores informales urbanos de las periferias de las grandes ciudades, que sienten el impacto de 
la falta de empleo y de derechos sociales. Los proyectos alternativos orientados para producir o generar ingresos se organizan alrededor de actividades como producción de artesanías, panadería o costura, con una alta participación de mujeres.

Estas actividades tienen inicialmente un cuño principalmente paliativo frente a situaciones de pobreza y miseria, y su significado en cuanto alternativa de organización económica comienza a ser objeto de discusión, primero dentro de los propios agentes promotores y posteriormente en espacios más amplios, donde se integran otros movimientos sociales, militantes políticos e intelectuales de la universidad, de cuyos encuentros y discusiones surgen las primeras ideas sobre lo que a mediados de la década de los 90 va a ser llamado de economía popular solidaria.

La revitalización de experiencias asociativas y cooperativas supone una retomada, pero también un cuestionamiento del sistema cooperativista existente, cuya penetración ha sido particularmente significativa en algunas regiones del estado. La economía solidaria surge demarcándose de estas prácticas y al mismo tiempo retomando sus principios normativos y organizativos más generales.

De hecho, cabe hacer notar que en Rio Grande do Sul —y de manera similar, en el resto del país- el cooperativismo es al mismo tiempo un antecedente y un eje de diferenciación para la economía solidaria. Sus límites, el tipo de opciones estratégicas y de dinámica organizacional, hacen que, en la década de 1980, las experiencias colectivas desarrolladas por diferentes actores del campo y de la ciudad asuman un claro proceso de diferenciación, que tiene como eje dos cuestiones fundamentales: de un lado, su base social, que crece significativamente en los medios urbanos; de otro, su identificación con un proyecto anticapitalista, de proyecto de sociedad, que no está presente en el cooperativismo tradicional. 
Desde el punto de vista del contexto más amplio, las «experiencias» de la década de 1980 permanecen sin gran visibilidad, muchas circunscritas a las acciones de algunas diócesis más activas y al espectro de agentes a ellas vinculados. De hecho, en esos años las atenciones están colocadas en las grandes luchas políticas que abren nuevos espacios a las fuerzas sociales de la democratización, cuyos sectores más a la izquierda se organizan en el Partido de los Trabajadores y cuyo punto máximo es la Constituyente, que genera la Constitución de 1988, el gran marco jurídico a través del cual se pensaba que se podría avanzar en los derechos sociales en el país. Movimientos importantes, como el de MST, están más preocupados en organizarse y cohesionar su base social, y el impulso de cooperativas y asociaciones es una de sus acciones pero no su prioridad.

\section{LA IDENTIFICACIÓN COMO «ECONOMÍA POPULAR SOLIDARIA»}

\section{Y SU PROGRESIVA ARTICULACIÓN CON REDES NACIONALES}

\section{E INTERNACIONALES}

El escenario político y económico cambia sensiblemente en los años 90, década caracterizada por la expansión neoliberal en América Latina, marcada por la apertura de la economía, que profundiza el aumento de las desigualdades sociales y del desempleo.

En este mismo periodo, Rio Grande do Sul aparece como un símbolo de la izquierda en Brasil, fundamentalmente en función de victorias electorales que consolidaron su principal bastión, la ciudad de Porto Alegre —en donde el Partido de los Trabajadores gobernó desde 1988 hasta 2002-, y llevaron al poder gobiernos de cuño popular en las principales ciudades, llegando a conquistar el gobierno estadual en 1999. 
En función de las nuevas circunstancias, el centro de las preocupaciones y de análisis se trasfiere hacia la búsqueda de mecanismos democráticos que amplíen la participación y el acceso a derechos. Los espacios formales de la política, hasta entonces vistos con desconfianza por el espectro del movimiento popular, pasan a ser entendidos como la gran esperanza de trasformación, vinculados con la ampliación de espacios participativos y de decisión, antes negados a las clases populares.

Paralelamente, el contexto de globalización económica y de crisis del modelo de industrialización y de regulación fordista, con sus consecuencias de aumento de desempleo y de desigualdad social, obligan a repensar las propuestas de desarrollo económico. Las fuerzas sociales y políticas que se oponen al neoliberalismo se ven delante del desafío de construir opciones concretas que se contrapongan al mismo, en las condiciones — ahora legitimadas — del sistema democrático establecido. Se imponen entonces discusiones conceptuales importantes: sobre el sistema, sobre los actores sociales del momento, sobre la relación con los aparatos de Estado y las políticas públicas.

Es en este contexto en el cual comienzan a ser reinterpretadas las prácticas económicas del mundo popular, y es en este periodo en el que el discurso de la economía solidaria se legitima y en el que el movimiento crece y se reconoce como tal, lo que puede ser constatado al comparar la situación al inicio y al final de la década. Efectivamente, en 1990-91 encontramos apenas algunas experiencias dispersas, un incipiente grado de articulación entre ellas y entre los agentes promotores y ninguna política pública; no hay todavía una identificación como economía solidaria.

En 1999, por el contrario, el número de experiencias es significativamente mayor (Sarria 2004), hay una autoidentificación con el nombre de «economía popular 
solidaria», un Foro de articulación de entidades y experiencias y varias alcaldías con políticas de promoción de la economía solidaria, iniciándose la discusión para la puesta en práctica de este tipo de políticas en el gobierno estadual. El cuadro también cambió en términos de movimientos y agentes implicados, entrando en el debate y en la acción algunas estructuras del movimiento sindical y un conjunto mayor de universidades, públicas y privadas. Estas trasformaciones pueden ser visualizadas en el Cuadro 1, al final del presente artículo.

Hasta 1995, el núcleo fundamental de gestación del movimiento de economía solidaria en Rio Grande do Sul estaba integrado por «actores del mundo popular urbano»y de «pequeños productores del mundo rural», animados por «agentes de la Iglesia católica» y algunas «ONG e intelectuales». El número de experiencias fue ampliándose progresivamente y se logró avanzar en la articulación del conjunto de actores integrados alrededor de la construcción de los proyectos alternativos, cuya principal fuerza dinamizadora era Cáritas, con articulaciones que crecían cuantitativa y cualitativamente, tanto en la ciudad - principalmente en Porto Alegre con la participación del gobierno municipal— como en el campo, principalmente con MST y su base de asentados a partir de la reforma agraria.

Es éste el conjunto de fuerzas que, ya en 1996, pasa a autoidentificarse bajo el término «economía popular solidaria», reunidos en los llamados Foros de entidades y Encontrones de experiencias alternativas, realizados entre 1995 y 1997. Este conjunto de fuerzas articuladas en torno a la economía solidara se configura cada vez más como una red integrada por una serie de actores «predispuestos a la acción» y animada por un imaginario común en que la oposición al neoliberalismo y la propuesta de una economía más justa juegan como elemento amplio de movilización. 
En 1995 se realiza el Foro de las entidades que actúan con Experiencias Alternativas de Organización Popular y Generación de Trabajo y Renta, del cual se configura una comisión que prepara el I Encontrón Estatal de Experiencias Alternativas de Organización Popular y Generación de Trabajo e Ingresos, desarrollado en agosto de 1996 junto con una pequeña Feria de muestra de productos. Esta actividad es de hecho el embrión de la organización de la economía solidaria en el estado. En ese mismo año se crea la «Supervisión de economía popular», dentro de la Secretaría de Industria y Comercio, SMIC, de la alcaldía de Porto Alegre. Ya en 1997, cuando se realiza nuevamente el Foro de Entidades, este asume el nombre de Foro de Economía Popular Solidaria. En 1998 tiene lugar el II Encontrón, que esta vez contempla el nombre de Encontrón de Economía Popular Solidaria.

Todo este proceso es impulsado por diferentes actores sociales que establecen lo que Doimo (1995) denomina «conexiones activas», características en el movimiento popular. Entre ellos, se destacan los siguientes:

- $\quad$ la Iglesia católica, representada fundamentalmente por Cáritas, así como otras pastorales sociales, como Pastoral de la Tierra, CPT, y en algunos lugares la Pastoral Obrera, PO;

- $\quad$ algunas ONG, que en el caso de Rio Grande do Sul se concretan en dos: Centro Ecuménico de Capacitación y Asesoría, CECA —expresión de sectores luteranos progresistas-, y Centro de Asesoría Multiprofesional, CAMP, de fuerte base de organización popular;

- $\quad$ espacio de política pública, recién creado en la alcaldía de Porto Alegre, denominado Supervisión de Economía Popular, representado por sus 
funcionarios, militantes de izquierda vinculados históricamente con otras luchas políticas y sociales;

- $\quad$ los intelectuales sensibilizados con la causa popular, que vienen principalmente de las universidades, tres en este caso, dentro de las cuales funcionan institutos o departamentos históricamente vinculados con acciones diversas de promoción del cooperativismo y de apoyo al movimiento popular: Universidad jesuita UNISINOS; Universidad comunitaria de Ijuí, UNIJUI, y la Universidad Federal de Rio Grande do Sul, UFRGS;

- $\quad$ los movimientos organizados, específicamente, el Movimiento de los Trabajadores Sin Tierra, MST, que se integra con relativa fuerza en el proceso de articulación; se ve interpelado por sus propios desafíos ya que, después de la conquista de la tierra por muchos de sus integrantes, su reto pasó a ser la organización productiva y cooperada de los mismos.

Las articulaciones entre estos actores fueron dándose en forma de una red, identificada con un imaginario común — la busca de alternativas al capitalismo, la organización popular-que fue progresivamente construyendo un discurso y un proyecto a partir del énfasis en la organización económica basada en la solidaridad y la cooperación.

La base social de esta red es heterogénea, integrada fundamentalmente por los mismos sectores que comenzaron la organización en los proyectos de generación de ingresos de la década anterior: los pobres del campo y la ciudad, específicamente los «pequeños productores del área rural» y los «sectores informales urbanos». 
La novedad de este proceso está dada por su énfasis en la organización de alternativas económicas, trayendo dos elementos nuevos al debate de la izquierda: por una parte, la cuestión de la economía popular y, por otra, la cuestión del cooperativismo.

La economía popular era hasta entonces identificada como economía informal y considerada como un residuo del capitalismo periférico, constituido por aquellos que no habían conseguido insertarse en el modelo industrial y que serían absorbidos cuando este se expandiese adecuadamente. El cooperativismo, por su parte, era visto como un sector dominado por una lógica empresarial en el que las formas jurídicas servían fundamentalmente para mantener relaciones de trabajo no protegidas por los derechos laborales.

Si bien desde los años 70 encontramos en las ciencias sociales un rescate positivo de la noción de «popular», recuperada como categoría analítica y como elemento simbólico con la imagen del «pueblo como sujeto de su propia historia» (Doimo 1995), este significado no se trasfirió para el análisis de las prácticas económicas de dichos sectores Según las lecturas marxistas clásicas, la base social de la economía solidaria - trabajadores informales urbanos y agricultores familiaresestaría referida a modelos de producción atrasados que «tenderían a desaparecer con el desarrollo de las fuerzas productivas», es decir, con la industria y con la mecanización de la agricultura.

En esa perspectiva, las experiencias de generación de trabajo y renta podían ser vistas como una forma de organización de la población frente al aumento del desempleo y de las desigualdades económicas, de carácter emergente y puntual, pero nunca como una estrategia de desarrollo económico y social viable. Sin embargo, la fuerza de las experiencias y las nuevas realidades enfrentadas provoca la construcción de nuevas 
perspectivas interpretativas, influenciadas por aportes de otros autores, latinoamericanos y europeos.

Es así como encontramos una influencia importante de autores como el chileno Luis Razeto (1997) y el argentino José Luis Coraggio (2000), a partir de los cuales se refuerzan dos ideas centrales: la de economía popular y su potencial, por un lado, y por el otro la construcción, dentro de ella, de un conjunto de organizaciones que funcionan de forma cooperada y solidaria. El concepto popular, por su parte, recubre una fuerza especial, tanto por su connotación política, pues la coalición de partidos que gobierna Porto Alegre en toda esa década es el Frente Popular; cuanto por su indicativo de opción por los pobres, recuperando el significado dado por la Iglesia católica a lo largo de todo su trabajo junto a los movimientos populares (Lechat 2003).

Entre 1998 y 1999 se estructura el Foro Metropolitano de Porto Alegre, a través del cual se articulan los grupos de economía solidaria de varios municipios de la región. Este es el primer espacio de organización de emprendimientos que se crea en Rio Grande do Sul. De hecho, a pesar de depender de los recursos y del apoyo gubernamental, la organización de este Foro representa un paso importante de articulación de emprendimientos y se constituye en un espacio de discusión e interlocución con el poder público y con las entidades de apoyo.

Los procesos de articulación estadual hasta entonces existentes se caracterizaban por ser principalmente de entidades, siendo la participación de emprendimientos más centrada en la comercialización de sus productos y sin un papel activo en la organización ni en los debates realizados. Esta cuestión de la organización de la base de la economía solidaria y su grado de autonomía o dependencia de los agentes promotores 
es un asunto que comienza a aparecer en los debates y que se constituye, hasta hoy, en uno de los desafíos de la economía solidaria en Brasil.

A partir de 1998, la economía solidaria pasa a ser promovida por otro núcleo importante de actores sociales, alterando su amplitud y su dinámica de funcionamiento. Este núcleo está constituido por un conjunto de «fuerzas provenientes del movimiento sindical», que retoman la historia de experiencias cooperativas y autogestionarias como parte de la lucha y resistencia de los trabajadores, reinterpretando su significado y pertinencia en el nuevo contexto del mundo del trabajo nacional y mundial. Este núcleo se constituye también estableciendo una conexión entre diversos actores e intelectuales vinculados con el mundo sindical y con la problemática industrial y de relaciones de trabajo, entre los cuales algunas organizaciones pasan a jugar un papel fundamental: la Asociación Nacional de Trabajadores de la Autogestión, ANTEAG; la Central Única de Trabajadores, CUT, ambas conectadas con un conjunto de intelectuales de la universidad que logran estructurar una Red Nacional de Universidades —Unitrabajoque desarrolla actividades de intervención y de investigación orientadas a promover y estudiar la economía solidaria.

Las primeras experiencias cooperativas en los espacios industriales surgieron con más fuerza en São Paulo, provenientes de la organización de trabajadores frente al cierre de empresas y la eliminación de puestos de trabajo $^{6}$ e identificadas alrededor de las ideas de la autogestión obrera. En 1994 es creada la ANTEAG, la cual surge con una doble función: «no solamente para ayudar a la lucha de los trabajadores por la preservación de sus puestos de trabajo y al mismo tiempo por el fin de su subordinación al capital, sino también para asesorar las nuevas empresas solidarias» (Singer 2002b: 89). 
En general, sin embargo, la organización cooperativa fue vista con desconfianza en el mundo sindical y, en función de eso, la economía solidaria solamente logrará entrar en pauta en los últimos años de la década de los 90. Singer relata que, dentro de la Central Única de Trabajadores, CUT, la entrada en la economía solidaria no fue fácil y «sufrió importante resistencia de sindicalistas, que identificaban el proceso con la tercerización de la mano de obra, que se daba cada vez más mediante la formación de seudocooperativas, con la única finalidad de robar de los trabajadores sus derechos laborales...». Otra oposición, de naturaleza ideológica, «apuntaba la necesidad de reforzar el trabajo asalariado por ser la base social de los sindicatos y porque solamente la clase operaria asalariada tendría por misión histórica derribar el capitalismo e instaurar el socialismo. Las cooperativas eliminarían el carácter de clase de los trabajadores, tornándolos [como] patrones y obreros al mismo tiempo» (Singer 2002b: 124).

La discusión sobre la economía solidaria fue avanzando poco a poco, y a finales de 1998 la ejecutiva nacional de CUT aprobó la creación de un grupo de trabajo sobre el asunto para, posteriormente, construirse un proyecto que desencadenó un proceso de discusiones en todo el país, el cual culminó en 1999 con el lanzamiento de la Agencia de Desarrollo Solidario, ADS-CUT (Singer 2002b: 125). Ya al final de esa década encontramos en Brasil diversas experiencias surgidas del mundo industrial y sindical, a través de las cuales los trabajadores desempleados comienzan a crear alternativas concretas de trabajo administradas por ellos mismos.

En Rio Grande do Sul la incidencia de este nuevo núcleo promotor se da fundamentalmente en los espacios universitarios y de articulación política, aunque tiene poca expresión en términos de experiencias de base. 
Dentro de las universidades, el interés y las acciones relacionadas con la economía solidaria se amplían significativamente, tanto en el ámbito de la investigación como en el trabajo de intervención. La promotora de ese interés creciente, conforme ya fue dicho, es la Red UNITRABAJO, que constituye un núcleo de economía solidaria coordinado por una de sus figuras más representativas: el profesor Paul Singer, economista y militante de la causa socialista, cuyo interés creciente por la experiencia de organización autogestionaria de la clase obrera europea a finales del siglo XIX lo lleva a teorizar sobre la economía solidaria y su carácter estratégico en Brasil.

Además de la constitución de grupos que realizan estudios sobre la economía solidaria se estructura una acción de extensión universitaria a través de la creación, en 1999, de la Red de Incubadoras de Cooperativas Populares, ITCP, cuyo objetivo es contribuir con la asesoría de emprendimientos de economía solidaria.

La relevancia que adquiere la economía solidaria dentro de sectores sindicales y de intelectuales de diversas universidades tiene por resultado principalmente proporcionarle mayor visibilidad e interés académico, aunque en términos concretos el universo de experiencias se mantuvo igual y con las mismas dificultades.

Por otra parte, en la medida en que las fuerzas de izquierda van consolidando nuevos espacios dentro del sistema político, principalmente en gobiernos locales e instancias parlamentarias, el debate sobre la economía solidaria pasa a ser objeto de interés — y de disputa — en el interior de las «fuerzas político-partidarias» propiamente dichas.

Hacia el final de la década de los 90, y principalmente a partir de 1999, por ocasión del inicio del gobierno de izquierda en el ámbito estatal, la economía solidaria pasa a integrar en su dinámica las contradicciones propias de su interacción con los 
espacios institucionalizados de poder, configurándose así un núcleo de agentes y de experiencias cuyo funcionamiento está fuertemente pautado por la lógica de los aparatos de gobierno y de la política partidaria.

Al mismo tiempo en que nuevos niveles de amplitud, organización y apoyo, son posibles, el movimiento y su proceso de articulación enfrentan los desafíos de mantener una postura autónoma y no de cooptación por parte de los aparatos de gobierno, teniendo que diferenciar y entender cada vez más las lógicas propias de cada uno. Estas contradicciones se profundizan en la siguiente década, y será en ese momento cuando las trataremos en profundidad.

\section{AMPLIACIÓN DEL MOVIMIENTO DE ECONOMÍA SOLIDARIA. IMPULSO Y CAPTURA POR LOS ESPACIOS INSTITUCIONALIZADOS}

La primera década del nuevo milenio inicia con señales de pérdida de impulso del neoliberalismo triunfante de los años 90, que se expresan dentro y fuera de Brasil, en la reactivación de la crítica y del debate sobre las alternativas a ese modelo, de diferente orden y alcance, así como en algunos cambios políticos que se evidencian principalmente en América Latina. En este proceso, la economía solidaria gana visibilidad y articulación internacional, integrándose como pauta de movimientos sociales y gobiernos de diferentes continentes. En Brasil, crece y se articula en la mayor parte del territorio nacional, impulsada principalmente por políticas de gobierno, que traen una serie de cambios importantes en sus características y dinámica de funcionamiento.

En este contexto, el estado de Rio Grande do Sul asume un lugar de referencia dentro de la economía solidaria, primero por la amplitud que aquí adquieren las políticas 
de gobierno en esta área, principalmente durante el periodo 1999-2002, cuando la administración estatal pasó a ser asumida por una coalición de izquierda que le dio impulso significativo; y segundo por la realización de cuatro ediciones del Foro Social Mundial en la ciudad de Porto Alegre, que convirtió la capital del estado en un palco privilegiado de encuentros e intercambios nacionales e internacionales.

Los años de la administración petista en el gobierno del estado dejaron una marca significativa en el proceso de organización de la economía solidaria pues, si por un lado se amplía su visibilidad y se estructura una red de emprendimientos a escala urbana y rural, por el otro cambia la dinámica de los procesos de intercambio y articulación que hasta entonces prevalecieron, los cuales pasan ahora a subordinarse a una pauta gubernamental que, por su parte, está atravesada por disputas propias de los espacios institucionalizados de la política, específicamente de las corrientes de izquierda que controlan los aparatos de poder en el ámbito estadual.

Quedan en evidencia así diferencias de concepción tanto en lo que se refiere a la relación estado-sociedad, como al potencial económico de los emprendimientos de la economía popular, pasando a ser enfatizada una lectura que privilegia los emprendimientos del sector industrial. Este debate sobre la economía solidaria supone la delimitación de paradigmas de fondo no siempre explicitados, los cuales expresan proyectos de desarrollo profundamente diferentes.

La derrota electoral de la izquierda para el gobierno del estado, a finales de 2002, marca la reversión del ciclo de ampliación de gobiernos de izquierda en Rio Grande do Sul, que culmina a finales de 2004 bajo el símbolo de la pérdida de la Prefectura de Porto Alegre, después de dieciséis años de administración petista (Sarria 2006). Este momento coincide, sin embargo, con el inicio de un conjunto de políticas 
públicas para la economía solidaria desde el gobierno federal, que crea, en 2003, la Secretaría Nacional de la Economía Solidaria, Senaes, generando así otro conjunto de modificaciones en el diseño organizacional de la economía solidaria en el marco nacional.

Este diseño organizacional es producto de la conjunción de tres procesos que caminan paralelos y se determinan mutuamente: de un lado, la «articulación nacional de un conjunto de organizaciones e intelectuales» que se identifican en la promoción de la economía solidaria y que intentan construir un discurso y una pauta común; por otro lado, la «articulación de esas organizaciones de intelectuales con redes internacionales» y su confluencia en los espacios creados a partir del Foro Social Mundial; finalmente, la «estructuración de políticas de gobierno para apoyo a la economía solidaria» y la disputa por ganar espacios en las diferentes esferas y áreas de actuación.

Es de esta interacción, activada a partir de la realización del I Foro Social Mundial en 2001, que se gesta la formación del Foro Brasileño de Economía Solidaria, FBES, el cual, coincidiendo con la victoria electoral de la izquierda para el gobierno federal, a finales de 2002, demanda espacios institucionales donde promocionar la economía solidaria y da lugar a la creación de la ya mencionada Secretaría Nacional de Economía Solidaria, Senaes. El Foro Brasileño de Economía Solidaria se funda oficialmente en 2003, en fechas coincidentes con la estructuración de Senaes, coincidencia ésta que pasa a ser representativa de los principales desafíos y contradicciones que se presentan a la economía solidaria brasileña en los últimos años.

El eje dinámico de estos procesos se dio fundamentalmente a partir de un conjunto de actores intermediarios y sus vínculos con actores globales especialmente activos al inicio de la década del año 2000, en un movimiento antiglobalización más 
amplio que dio cauce a diferentes formas de protesta y de propuestas de alternativas. Sin embargo, los grupos de base — los «emprendimientos de economía solidaria»— no tuvieron una participación activa, funcionando apenas como «paño de fondo» o «razón de ser» de las construcciones de los espacios de interlocución de carácter macro —nacionales, regionales e internacionales_ para la economía solidaria. Esta situación generó una discusión y una disputa permanente sobre el «protagonismo» o la dependencia de los emprendimientos, siendo posible identificar un conjunto de desafíos que prepasan la economía solidaria hoy.

Fue en medio de estos desafíos y contradicciones que se constituyeron los foros en los estados y regiones, los cuales pasaron a ser el espacio de organización de un movimiento de economía solidaria cuya base continuó siendo prácticamente la misma de sus orígenes, centrada en grupos informales de las periferias urbanas y de la agricultura familiar, aunque ésta se expande significativamente a partir de $2001{ }^{7}$ Hay también un aumento de la presencia de trabajadores del sector industrial, creándose algunas empresas recuperadas, principalmente en el sector metalúrgico. ${ }^{8}$ El Cuadro 1, al final de esta sección, muestra el espectro de la economía solidaria en Rio Grande do Sul en 2005.

En términos de movilización y participación, son los trabajadores de los sectores populares urbanos los que asumen principalmente «la causa» de la economía solidaria, marcando presencia en las actividades organizadas por los foros, entre las cuales las ferias de comercialización mantienen un lugar privilegiado. Estos trabajadores se mantienen circunscritos en ciertos grupos y asociaciones, configurando un espacio de relaciones y de participación que, aunque bastante intenso, no logra ampliarse a otros espacios de las comunidades donde actúan. 
Progresivamente, el vínculo con el movimiento popular que animó las experiencias de economía solidaria en sus inicios va dando lugar a una identificación con políticas de gobierno. Los agentes —Iglesia, ONG, intelectuales, movimientosque impulsaron las experiencias de economía solidaria en los años 90 continúan activos, pero pasan a ser pautados por dinámicas más institucionales, perdiendo mucho de los impulsos autonomistas que los caracterizaron. Si antes ellos servían de activadores de una acción de base en dirección a la ampliación de espacios institucionales, ahora pasan a estar cada vez más orientados por la pauta que viene «de arriba», desde los nuevos espacios que se abren en las instituciones políticas, dando cabida a nuevas voces y capturándolas al mismo tiempo en su lógica decisoria de poder.

Esta problemática, en realidad, atraviesa la discusión de la mayor parte de los movimientos sociales en el país, ampliando los debates sobre su relación con los espacios institucionalizados del poder, sobre su papel en la profundización de la democracia y su capacidad de generar espacios públicos autónomos preparados para activar la acción crítica frente a la lógica unificadora de ese mismo poder. 
Cuadro 1. Génesis de la economía solidaria en Rio Grande do Sul. Sus actores en 2005*

\begin{tabular}{|c|c|c|c|}
\hline & \multicolumn{3}{|c|}{ Espacios de actuación } \\
\hline & Periferia de las grandes ciudades & Área rural & Industrias \\
\hline $\begin{array}{c}\text { Tipo de } \\
\text { experiencias }\end{array}$ & 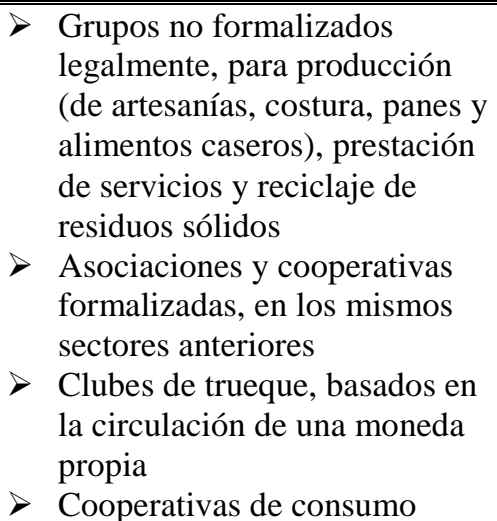 & $\begin{array}{l}\text { Grupos y asocia- } \\
\text { ciones diversas, para } \\
\text { producción y } \\
\text { comercialización de } \\
\text { productos de } \\
\text { agricultores } \\
\text { familiares } \\
\text { Cooperativas de } \\
\text { producción y } \\
\text { comercialización }\end{array}$ & $\begin{array}{l}\text { Empresas recuperadas } \\
\text { (varias en el sector } \\
\text { metalúrgico) } \\
\text { Cooperativas de } \\
\text { calzado, que realizan } \\
\text { una parte del proceso } \\
\text { productivo de grandes } \\
\text { empresas }\end{array}$ \\
\hline Base social & $\begin{array}{l}\text { Trabajadores por cuenta } \\
\text { propia, en condiciones de } \\
\text { desempleo o subempleo, con } \\
\text { significativa presencia } \\
\text { femenina }\end{array}$ & $\begin{array}{l}\text { Pequeños agricultores } \\
\text { en condiciones de } \\
\text { minifundio y con una } \\
\text { base productiva } \\
\text { diversificada } \\
>\text { Asentados de la } \\
\text { reforma agraria }\end{array}$ & 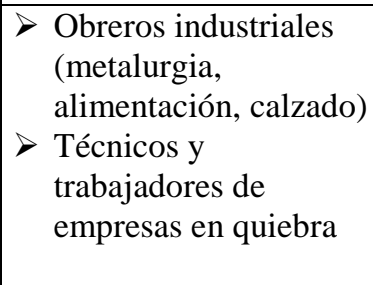 \\
\hline $\begin{array}{l}\text { Movimientos } \\
\text { sociales } \\
\text { implicados }\end{array}$ & $\begin{array}{l}\text { Asociaciones de barrio, clubes } \\
\text { de madres, etcétera } \\
\text { Marcha Mundial de las } \\
\text { Mujeres }\end{array}$ & $\begin{array}{l}\text { MST, Movimiento de } \\
\text { los trabajadores sin } \\
\text { tierra } \\
>\text { Movimiento Negro, } \\
\text { Quilombolas } \\
>\text { Movimiento de los } \\
\text { pequeños agricultores }\end{array}$ & $\begin{array}{l}\text { CUT, Central Única } \\
\text { de Trabajadores }\end{array}$ \\
\hline $\begin{array}{l}\text { Organizaciones } \\
\text { de apoyo }\end{array}$ & $\begin{array}{l}\text { Cáritas de Rio Grande do Sul } \\
\text { y de algunas diócesis } \\
>\text { CAMP (Centro de Asesoría } \\
\text { Multiprofesional) } \\
>\text { GUAYI } \\
>\text { Escuela } 8 \text { de marzo } \\
>\text { AVESOL (Marista) } \\
>\text { ATES (Pelotas) } \\
>\text { CAEPS (Paso Fundo) } \\
>\text { Otras, con actuación local }\end{array}$ & $\begin{array}{l}\text { Cáritas de Rio Grande } \\
\text { do Sul y de algunas } \\
\text { diócesis (Passo } \\
\text { Fundo, Santa María, } \\
\text { Pelotas) } \\
\text { CAMP (Centro de } \\
\text { Asesoría } \\
\text { Multiprofesional) }\end{array}$ & $\begin{aligned} & \text { ADS, Agencia de } \\
& \text { desarrollo solidario } \\
& \text { ANTEAG, Asociación } \\
& \text { de trabajadores de la } \\
& \text { autogestión } \\
> & \text { UNISOL Brasil }\end{aligned}$ \\
\hline $\begin{array}{l}\text { Universidades } \\
\text { involucradas }\end{array}$ & $\begin{array}{l}\text { Red UNITRABAJO: UNISINOS, I } \\
\text { Red ITCP: UCPEL, FURG, UFRG }\end{array}$ & $\begin{array}{l}\text { NIJUI } \\
\text { UNILASALLE, FEEVAL }\end{array}$ & \\
\hline $\begin{array}{l}\text { Políticas de } \\
\text { gobierno }\end{array}$ & $\begin{array}{l}\text { Alcaldías de Porto Alegre, } \\
\text { Viamão, São Leopoldo e } \\
\text { outros. } \\
\text { 1999-2002- gobierno del } \\
\text { estado (departamento } \\
\text { ecopopsol) } \\
\text { 2003-gobierno federal } \\
\text { (SENAES), otros ministerios. }\end{array}$ & $\begin{array}{l}\text { EMATER: programas } \\
\text { de asistencia técnica a } \\
\text { pequeños agricultores. } \\
\text { MDA (Min. de } \\
\text { Desarrollo Agropec.): } \\
\text { programas de apoyo a } \\
\text { la agricultura familiar }\end{array}$ & $\begin{array}{l}\text { BNDES: líneas de crédito } \\
\text { para empresas } \\
\text { recuperadas }\end{array}$ \\
\hline
\end{tabular}

*El espacio sombreado indica los elementos nuevos de la década de 2000.

Fuente: Elaboración propia. 


\section{CONSIDERACIONES GENERALES}

La revisión del origen y trayectoria de la economía solidaria en Rio Grande do Sul nos muestra cómo esta surge principalmente delineada a partir de actores sociales de diversas orígenes — campesinos, clases populares urbanas, trabajadores desempleados, agentes sociales y religiosos, intelectuales- que se congregan para construir nuevos significados y propuestas de organización económica y social, urgidos por los conflictos de una sociedad en que nuevos impulsos democráticos chocan con un autoritarismo de base y en que las esperanzas de mejoría de vida se contraponen al aumento de las desigualdades y a la crisis del modelo de desarrollo que hasta entonces prevaleció.

La novedad de las experiencias de economía solidaria es que activan la búsqueda - y el rescate — de formas de solidaridad capaces de hacer un contrapunto a la lógica excluyente con que el mercado funciona. Al mismo tiempo, exponen las contradicciones y fragilidades de las visiones de desarrollo dominantes, colocando en práctica otras formas de organización de la vida y de la producción, haciendo emerger actores sociales donde antes se veían apenas masas empobrecidas a la espera de la modernización.

Llama la atención el rápido proceso de crecimiento en los últimos diez años, tanto desde el punto de vista de su tejido organizacional como de las políticas públicas que la promueven. En este proceso, la dinámica de «movimiento» que anima la economía solidaria, caracterizada por el encuentro de actores diversos movilizados para la organización de experiencias económicas asociativas, pasa por un fuerte proceso de «institucionalización», ampliando su cobertura y legitimidad en ritmo bastante acelerado, condicionada por dos procesos paralelos: por un lado, la estructuración de espacios formales de representación - los Foros-, y por el otro la estructuración de 
políticas de promoción de economía solidaria en diferentes ámbitos, desde la esfera local hasta la nacional.

Se destaca entonces el desafío democrático de la economía solidaria, que supone la participación activa de sus actores de base como protagonistas y no apenas como objeto de propuestas de organización económica cooperativa impulsadas por el Estado o las organizaciones de promoción y apoyo. Las experiencias de economía solidaria expresan procesos de organización de diversos actores sociales que se unen no solo para producir y consumir sino también para incidir en la propia lógica de funcionamiento de la sociedad, de la cual históricamente se vieron excluidos. El desafío es justamente la ampliación de espacios públicos democráticos en los que puedan afirmarse las demandas y las prácticas de esos actores sociales, lo que se contrapone con una visión restricta a la disputa de los espacios de representación política y al control de los aparatos de gobierno.

En este sentido, el análisis muestra el confronto de visiones y la ambigüedad de las prácticas de los foros regionales y de los diversos actores sociales que participan de la economía solidaria, que se constituyen con una importante dinámica instituyente, de ampliación de espacios públicos a diferentes escalas, pero tienden progresivamente a restringirse a la dinámica de los espacios institucionalizados, en los cuales se reproducen viejas y nuevas prácticas autoritarias o de cooptación política.

Estas contradicciones son más fuertes cuanto más se amplían los programas de gobierno en todas las esferas, explicitando un proceso que es inherente al impulso democratizador de la economía solidaria: por un lado, la incidencia en la ampliación de los espacios institucionales —en el caso brasileño, los programas de gobierno existen y se expanden en función de la propia demanda de los actores sociales-, y por otro la 
necesidad de mantener autonomía delante de los impulsos de «captura» por parte de los sistemas institucionalizados de poder. 


\section{BIBLIOGRAFÍA}

Arruda, Marcos, 1996, «Globalização e sociedade civil. Repensando o cooperativismo no contexto da cidadania ativa». Conferencia sobre Globalización y Ciudadanía, organizada por el Instituto de Investigaciones de la ONU para el Desarrollo Social, 9-11 de diciembre, mecanuscrito, Ginebra.

Bertucci, Ademar y Roberto Silva, (eds.), 2003, Vinte anos de economia popular solidária: trajetória da Cáritas. Cáritas Brasileira, Brasília.

Central Única dos Trabalhadores, CUT, 1999, Sindicalismo e economia solidária: reflexões sobre o projeto da CUT. CUT, São Paulo.

Coraggio, José Luis, 2000, «Da economia dos setores populares à economia do trabalho». En Economia dos setores populares: entre a realidade e a utopia, Gabriel Kraychete, Francisco Lara y Beatriz Costa (eds.). Vozes, Capina, CESE, UCSAL, Brasil.

2001, «Problematizando la economía solidaria y la globalización alternativa». Presentación en el II Encuentro Internacional sobre la globalización de la solidaridad, 9-12 de octubre, mecanuscrito, Quebec.

Doimo, Ana María, 1995, A vez e a voz do popular. Movimentos sociais e participação política no Brasil pós-70. Relume-Dumará, ANPOCS, Rio de Janeiro.

Fraisse, Laurent, 2003, «Économie solidaire et démocratisation de l'économie». En Hermès, núm. 36, p. 137-145. Économie Solidaire et Démocratie. CNRS Editions, Paris. 
Gaiger, Luiz Inácio et alli, 1999, A economia solidária no $R S$ : Viabilidade $e$ Perspectivas. Cadernos do CEDOPE, Série Movimentos Sociais e Cultura. Unisinos, São Leopoldo.

França Filho, Genauto Carvalho y Jean-Louis Laville, 2004, Economia Solidária: uma abordagem internacional. Editora da UFRGS, Porto Alegre.

Gohn, Maria da Glória, 1997, Teorias dos movimentos sociais. Paradigmas clássicos e contemporâneos. Loyola, São Paulo.

Laville, Jean-Louis (ed.), 2006, Ação Pública e Economia Solidária. Uma perspectiva internacional. Editora da UFRGS, Porto Alegre.

Lechat, Noelle, 2003, As raízes históricas da economia solidária e seu aparecimento no Brasil. II Seminário de incubadoras tecnológicas de cooperativas populares, mimeo. Campinas.

Lisboa, Armando de Melo, 2000, «Os desafios da economia popular solidária». Cadernos do CEAS, núm. 189, pp. 51-67, octubre. Salvador.

Mance, Euclides, 1999, A revolução das redes: a colaboração solidária como uma alternativa pós-capitalista à globalização atual. Vozes, Petrópolis.

Peemans, Jean-Philippe, 2002, Le développement des peoples face à la modernization du monde. Louvain-la-Neuve, Bruylant-Academia. 
Quijano, Aníbal, 1999, Economia de solidariedade e organização popular». En Educação comunitária e economia popular, M. Gadotti y F. Gutiérrez (eds.), pp. 34-58, 2da. Edição. Coleção questões da nossa época, v. 25. Cortez, São Paulo.

2002, «Sistemas alternativos de produção?». En Produzir para viver. Os caminhos da produção não capitalista, Boaventura de Souza Santos (ed.), pp. 475-512. Civilização Brasileira, Rio de Janeiro.

Razeto, Luis, 1997, «Los caminos de la economía de solidadridad». Buenos Aires, Editorial Lumen-Hvmanitas.

Singer, Paul, 2002a, Introdução à Economia Solidária. Editora Fundação Perseu Abramo, São Paulo.

2002b, «A recente resurreição da economia solidária no Brasil». En Produzir para viver; os caminhos da produção não capitalista, Boaventura Santos (ed.). Civilização Brasileira, Rio de Janeiro.

Sarria Icaza, Ana Mercedes, 2004, «Solidariedade, autogestão e cidadania: mapeando a economia solidária no Rio Grande do Sul». En Sentidos e experiências da Economia Solidária no Brasil, L. I. Gaiger. Editora da UFRGS, Porto Alegre.

2006, «Les politiques publiques pour l'économie solidaire au Rio Grande do Sul (Brésil): La dynamique des acteurs et des institutions». En Economie solidaire et commerce équitable. Acteurs et actrices d'Europe et d'Amérique latine, Claude Auroi e Isabel Yépez del Castillo (eds.). Presses Universitaires de Louvain, Institut Universitaire d'études du Développement, Ginebra. 


\section{Notas}

\footnotetext{
${ }^{1}$ Un autor de referencia de esta perspectiva es Paul Singer (2002a, 2002b); ver también Arruda (1996) y Mance (1999).

${ }^{2}$ Ver, entre otros, Lisboa (2000), Coraggio (2000), Quijano (2002).

${ }^{3}$ Ver, entre otros, Laville (2006), Fraise (2003), França Filho y Laville (2004).

${ }^{4}$ Es ilustrativa la experiencia de Porto Alegre, capital del estado, gobernada por el Partido de los Trabajadores desde 1989, y cuyo «presupuesto participativo» es una referencia internacional.

${ }^{5}$ En Rio Grande do Sul, por motivos históricos y de influencias diversas se prefiere la denominación de «economía popular solidaria», pero se acepta sin cuestionamientos de fondo la utilización nacional del término «economía solidaria».

${ }^{6}$ En realidad, Rio Grande do Sul cuenta con una de las primeras industrias asumida por los trabajadores, como resultado de un proceso de concordata. Se trata de la empresa de cocinas Walig, en Porto Alegre. Esta experiencia, sin embargo, permaneció aislada del movimiento que se constituyó en el inicio de los años 90 y dio lugar al surgimiento de Anteag.

${ }^{7}$ Conforme datos del Sistema de Información para la Economía Solidaria, en Rio Grande do Sul, de los 1,568 emprendimientos que comenzaron después de 1981, 731 (47\%) iniciaron después de 2001.

${ }^{8}$ Entre éstas cabe destacar Geralcoop, en Canoas, y CTMC en Guaíba.
}

Fecha de recepción: 26 de marzo de 2008.

Fecha de aceptación: 02 de octubre de 2008. 